\title{
Direct Oral Anticoagulants in End-Stage Renal Disease
}

\author{
Adi J. Klil-Drori, MD ${ }^{1}$ Vicky Tagalakis, MD, MSc ${ }^{1,2}$ \\ ${ }^{1}$ Center for Clinical Epidemiology, Lady Davis Institute, Jewish \\ General Hospital, Montreal, Quebec, Canada \\ ${ }^{2}$ Department of Medicine, McGill University, Montreal, \\ Quebec, Canada
}

\begin{abstract}
Address for correspondence Adi J. Klil-Drori, MD, Center for Clinical Epidemiology, Jewish General Hospital, Montreal, QC H3T 1E2, Canada (e-mail: adi.klil-drori@mail.mcgill.ca).
\end{abstract}

Semin Thromb Hemost 2018;44:353-363.

\begin{abstract}
Patients with end-stage renal disease (ESRD) were excluded from pivotal clinical trials with oral anticoagulants. While such patients are at an increased risk of venous and arterial thromboembolism, their risk of bleeding is also elevated. It is thus of little surprise that stroke prevention with vitamin $\mathrm{K}$ antagonists (VKAs) in ESRD patients with atrial fibrillation is controversial, with observational evidence ranging from beneficial to

Keywords

- anticoagulants

- renal dialysis

- kidney failure

- chronic

- venous thrombosis

- stroke

harmful. This uncertainty extends to the less studied use of VKAs for venous thromboembolism in ESRD. The direct oral anticoagulants (DOACs) apixaban and rivaroxaban have now permissive labeling in the United States for atrial fibrillation in patients with ESRD; this expanded labeling has not yet occurred either in Europe or for venous thromboembolism. This review summarizes the current evidence for the pharmacology of DOACs in ESRD as well as their utilization and safety in patients with ESRD and atrial fibrillation.
\end{abstract}

Chronic kidney disease (CKD), usually defined as glomerular filtration rate $($ GFR $)<60 \mathrm{~mL} / \mathrm{min} / 1.73 \mathrm{~m}^{2}$ for at least 3 months, ${ }^{1}$ affects $\sim 7 \%$ of adults in the United States. ${ }^{2,3}$ Estimates of CKD prevalence vary by country and region and are associated with population aging and economic status. ${ }^{4}$ CKD is caused by four conceptual mechanistic pathways: glomerular diseases (e.g., diabetic nephropathy), tubulointerstitial diseases (e.g., myeloma), vascular diseases (e.g., hypertension), and cystic/congenital diseases (e.g., renal dysplasia). ${ }^{1}$ A decline of GFR to $<15 \mathrm{~mL} / \mathrm{min} / 1.73 \mathrm{~m}^{2}$ defines kidney failure, or end-stage renal disease (ESRD), which is an indication for renal replacement therapy (RRT; dialysis or renal transplantation). By 2014, more than a million individuals in the United States and Europe combined were receiving RRT, representing a marked increase in the prevalence of ESRD. ${ }^{3,5}$ Patients with ESRD and atrial fibrillation (AF) have an increased risk of stroke, compared with less severe renal impairment. ${ }^{6}$ Furthermore, the prevalence of AF in the hemodialysis population is 13 to $27 \%$, or 10 - to 20 -fold higher than in the general population. ${ }^{7}$ The risk of venous thromboembolism
(VTE) is also positively correlated with CKD, suggesting ESRD is a hypercoagulable state. ${ }^{8,9}$ Such thrombotic risk could be explained by various factors, including inherited thrombophilia, ${ }^{10}$ vascular access-related problems, ${ }^{11}$ and increased concentrations of procoagulant factors. ${ }^{6}$ Thus, patients with ESRD have multiple indications for the use of oral anticoagulants. Nonetheless, data on oral anticoagulant use for VTE in patients with ESRD are scarce; thus, studies reviewed below are primarily in the AF population.

\section{Search Strategy}

Published studies and conference proceedings in English were searched using PubMed, EMBASE, and the Cochrane database. Search terms included: dialysis, end stage renal disease, vitamin K antagonists (VKAs), apixaban, dabigatran, rivaroxaban, edoxaban, atrial fibrillation, venous thromboembolism, and bleeding. In addition, reference lists of narrative and systematic reviews were manually searched for peer-reviewed publications. Where multiple publications
Issue Theme Recent Advances in Thrombosis and Hemostasis - Part III; Guest Editor: Sam Schulman, MD, PhD.
Copyright $\odot 2018$ by Thieme Medical Publishers, Inc., 333 Seventh Avenue, New York, NY 10001, USA. Tel: +1(212) 584-4662. 
existed from the same data source, the most recent was reviewed. Finally, abstracts from international conferences were manually searched for relevant publications.

\section{Vitamin K Antagonists}

\section{Pharmacology in ESRD}

Vitamin $\mathrm{K}$ antagonists (VKAs), including warfarin, reflect the mainstay of treatment and prevention of thromboembolic disease in ESRD. Warfarin has a near 100\% bioavailability, and reaches peak concentration within 4 hours of absorption. Elimination of warfarin is almost entirely via metabolism, and renal clearance is negligible. ${ }^{12}$ However, in patients with ESRD, nonrenal clearance is diminished through downregulation of cytochrome $\mathrm{P} 450$ gene expression. ${ }^{13} \mathrm{~A}$ consequent increase in the $S /$ Renantiomer ratio ${ }^{14}$ is the putative explanation for three important observations in ESRD patients: (1) reduced warfarin dose requirements ${ }^{15}(2)$ diminished time in therapeutic range regardless of international normalized ratio (INR) intensity; ${ }^{16}$ and (3) increased time with excessive INR. ${ }^{17}$ Nonetheless, decreased protein binding in ESRD ${ }^{18}$ probably accounts for the $31 \%$ drop in warfarin concentration following hemodialysis, owing to partial filtration of unbound warfarin. ${ }^{19}$ Further, reduced protein binding is the likely cause of the shortened half-life of warfarin in patients with CKD, which is 30 hours compared with 45 hours in subjects with normal kidney function (-Table 1). ${ }^{20}$

\section{Utilization Patterns in ESRD}

The effectiveness and safety of VKA among patients with ESRD and AF is highly debated, ${ }^{21,22}$ as reflected in the wide variability of VKA use among patients with ESRD in different high-income countries. ${ }^{23}$ Similarly, studies from the United States preceding market availability of the direct oral anticoagulants (DOACs) report a 15.5 to $62.3 \%$ prevalence of VKA use in patients on dialysis with incident $A F^{16,24}$ One further concern with VKA use for stroke prevention is low persistence over time, or early discontinuation. ${ }^{25}$ Indeed, almost half of dialysis patients with AF initiated on VKA were found to discontinue the drug within less than 9 months of use and without switching to DOACs. ${ }^{24}$

\section{Safety in ESRD}

The presence of ESRD confers a bleeding diathesis independent of oral anticoagulation, manifesting as major, but also as nonmajor bleeding events. ${ }^{17}$ In hemodialysis patients, repetitive activation of platelets is thought to lead to platelet "exhaustion" and consequent dysfunction. ${ }^{26}$ Several studies have been published on bleeding risk with VKA among patients with ESRD ( - Table 2). While differing in study design and methodology, most of the larger ( $>100$ VKA users) studies reported major bleeding rates of 10 per 100 person-years or higher. In comparison, the pivotal clinical trials with DOACs, which excluded patients with severe CKD or ESRD, reported bleeding rates of $\sim 3$ per 100 person-years in the VKA arm. ${ }^{27-30}$ This comparison emphasizes the bleeding diathesis in ESRD rather than the comparative risk of bleeding with VKA versus no use, which varies with reports.
A further safety concern with VKA use in ESRD is increased risk of calcific uremic arteriolopathy (or calcific vasculopathy), which leads to ischemic skin necrosis. ${ }^{31}$ This syndrome is prevalent in $\sim 4 \%$ of hemodialysis recipients and is associated with a case-fatality rate of $27 \%$ at 6 months and $45 \%$ at 12 months. $^{32}$ In a cohort of 1,030 patients on hemodialysis, the incidence rate of calcific uremic arteriolopathy was 6.24 versus 3.35 per 1,000 person-years in VKA users and nonusers, respectively. ${ }^{32}$

\section{Dabigatran}

\section{Pharmacology in ESRD}

Dabigatran, a direct thrombin inhibitor, is the active metabolite of the prodrug dabigatran etexilate. Renal clearance is appropriately estimated with intravenous infusion; after such infusion, $81 \%$ of the dose is recovered in urine, with $80 \%$ renal contribution to the total clearance. ${ }^{33}$ Thus, dabigatran has the highest renal clearance among DOACs (-Table 1). Exposure to dabigatran is negatively correlated with renal function, and the area under the plasma concentration-time curve (AUC) is 6.3-fold higher in patients with severe CKD after a single oral dose, compared with healthy subjects. ${ }^{34}$ Accordingly, 150 - or 110 -mg dabigatran are not indicated in Europe in patients with severe CKD or ESRD (-Table 3). ${ }^{35}$ The Food and Drug Administration (FDA) has approved the use of a 75-mg dose in patients with GFR between 15 and $30 \mathrm{~mL} / \mathrm{min} / 1.73 \mathrm{~m}^{2}$ based on pharmacokinetic studies, but offers no dosing recommendations for ESRD. ${ }^{36}$ Of note, a simulation study suggested that a 75 - or $110-\mathrm{mg}$ dose taken once daily would result in therapeutic exposure to dabigatran in hemodialysis patients. ${ }^{37}$ Dabigatran is dialyzable, and 50 to $60 \%$ of central compartment dabigatran can be removed by a single 4-hour dialysis. ${ }^{38}$ Whether this remains a viable option for dabigatran removal in urgent bleeding or need for urgent procedure (where anticoagulation should be stopped abruptly) following idarucizumab approval remains to be seen. ${ }^{39}$ Hemodialysis for dabigatran removal has been suggested when idarucizumab is not available, and caution should be exercised for a resumed anticoagulant effect at the end of the dialysis session. ${ }^{40}$

\section{Utilization Patterns in ESRD}

Dabigatran was approved by the FDA for use in AF in October 2010, reaching this mark first among the DOACs. In the United States, the $75-\mathrm{mg}$ dose is recommended in patients with GFR between 15 and $30 \mathrm{~mL} / \mathrm{min} / 1.73 \mathrm{~m}^{2}$, while in Europe, the $110-\mathrm{mg}$ dose is recommended for patients with GFR between 30 and $49 \mathrm{~mL} / \mathrm{min} / 1.73 \mathrm{~m}^{2}$ and high risk for bleeding (- Table 3). ${ }^{35}$ As noted previously, dabigatran is not approved in Europe for patients with severe CKD.

Prescription pattern analysis from Europe suggests CKD is a predictor for preferring VKA over DOACs for VTE, with dabigatran in either dose not prescribed at all in severe CKD. ${ }^{41}$ In the United States, the 75-mg dose was used in up to $3 \%$ of dialysis patients with $\mathrm{AF}$ who were being anticoagulated shortly after its approval. ${ }^{42}$ However, the 


\begin{tabular}{|c|c|c|c|c|c|c|c|c|c|c|c|}
\hline 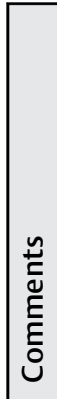 & & & & & 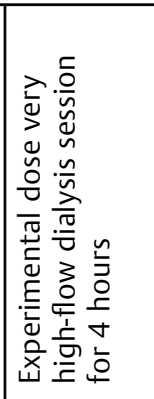 & 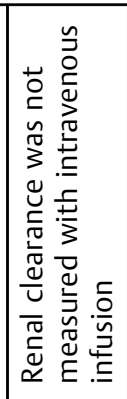 & 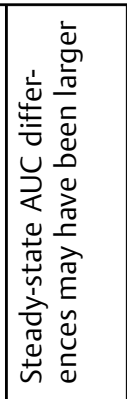 & & & 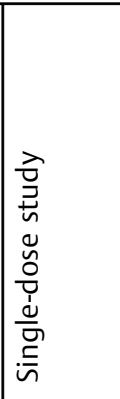 & 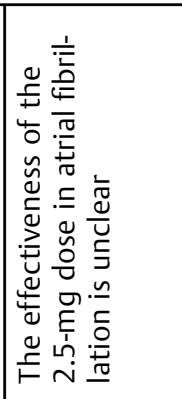 \\
\hline 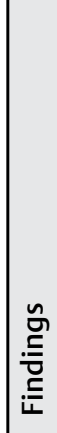 & 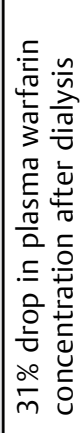 & 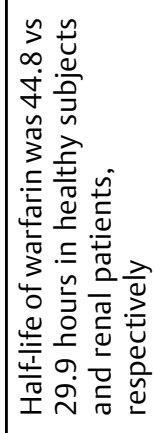 & 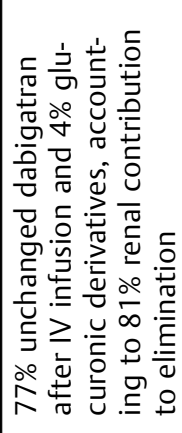 & 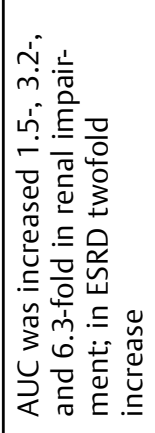 & 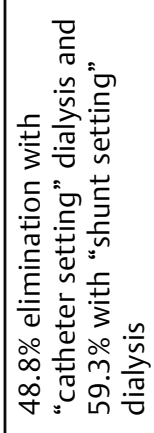 & 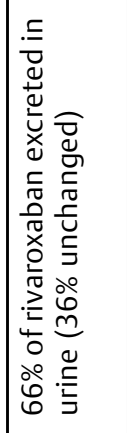 & 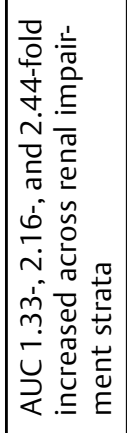 & 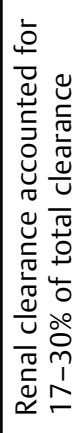 & 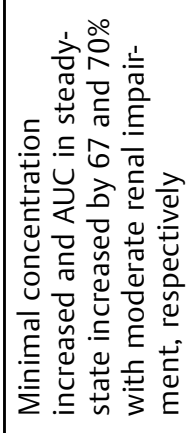 & 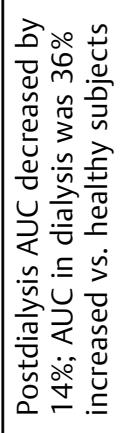 & 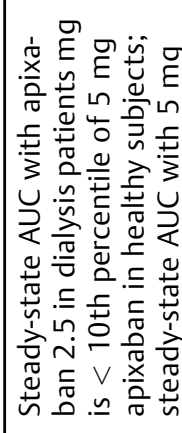 \\
\hline 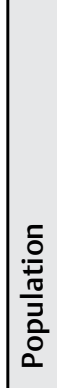 & 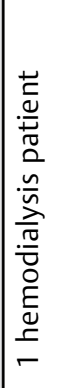 & 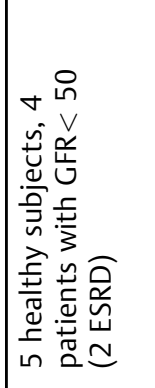 & 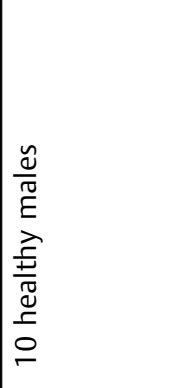 & 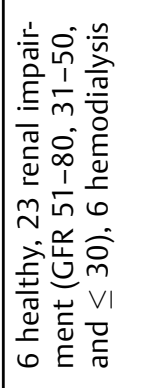 & 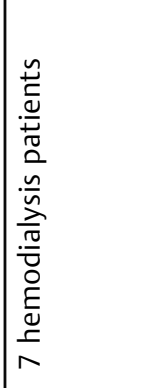 & 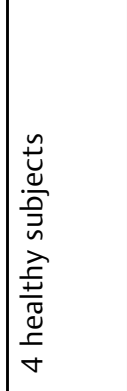 & 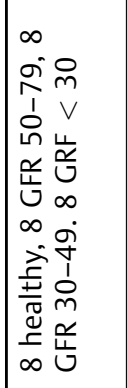 & 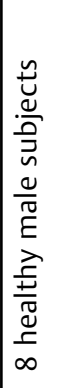 & 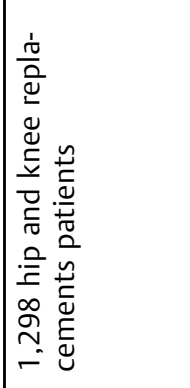 & 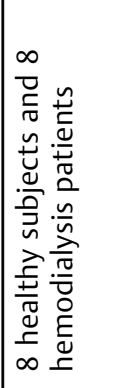 & 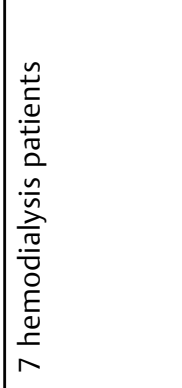 \\
\hline 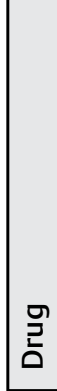 & 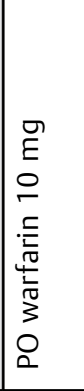 & 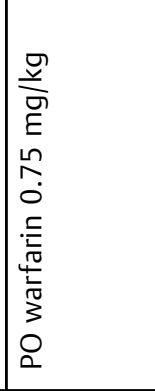 & 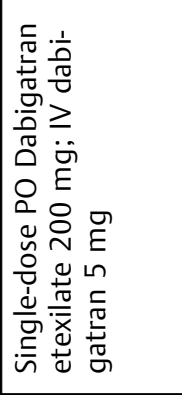 & 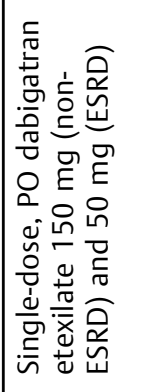 & 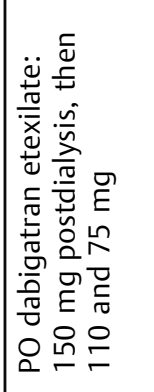 & 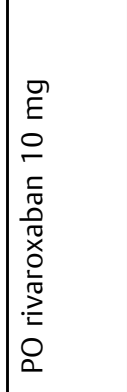 & 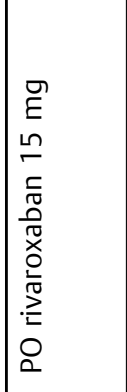 & 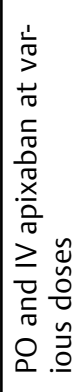 & 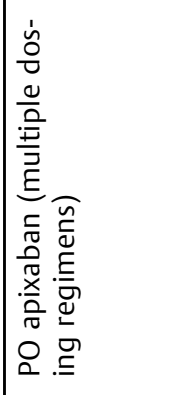 & 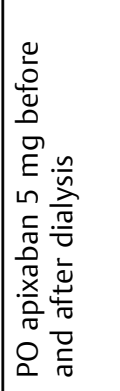 & 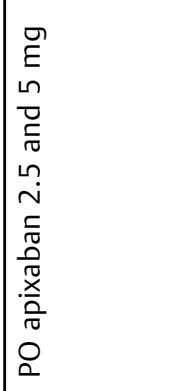 \\
\hline $\begin{array}{l}\text {. } \\
\bar{y}\end{array}$ & 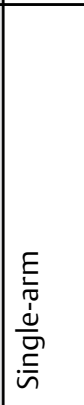 & 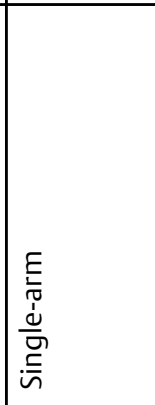 & 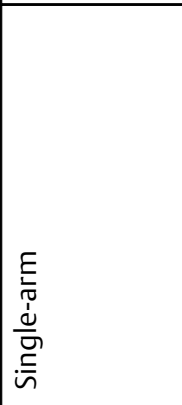 & 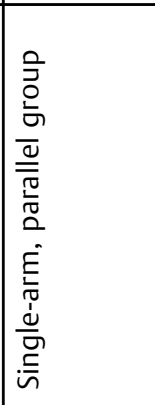 & 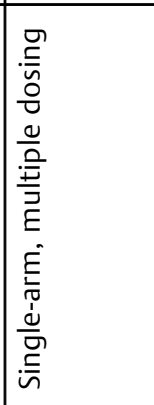 & 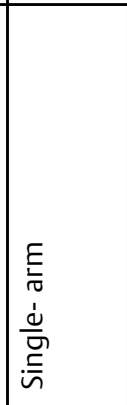 & 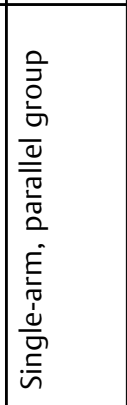 & 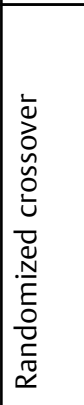 & 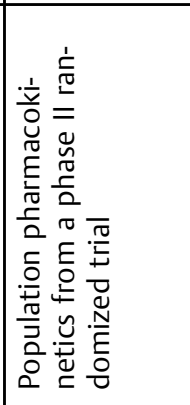 & 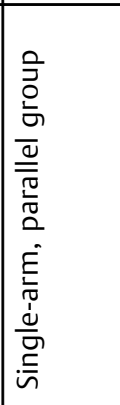 & 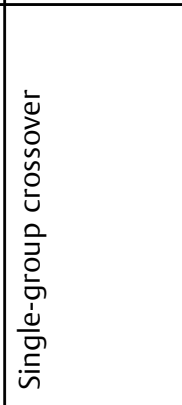 \\
\hline $\begin{array}{l}\text { ते } \\
\text { जे }\end{array}$ & 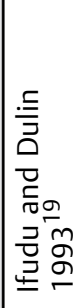 & 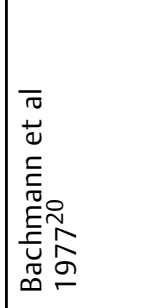 & 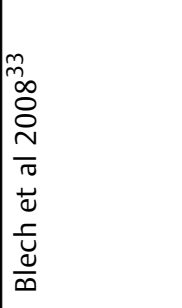 & 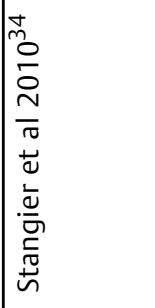 & 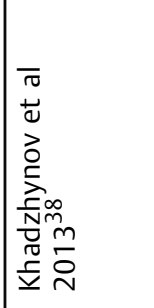 & 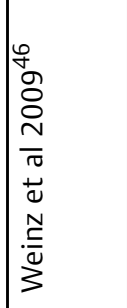 & 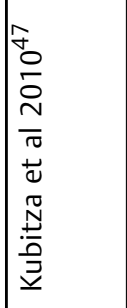 & 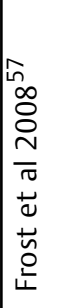 & 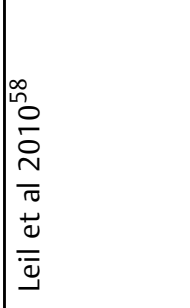 & 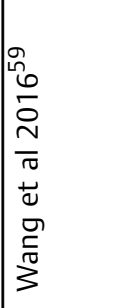 & 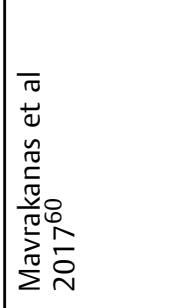 \\
\hline
\end{tabular}




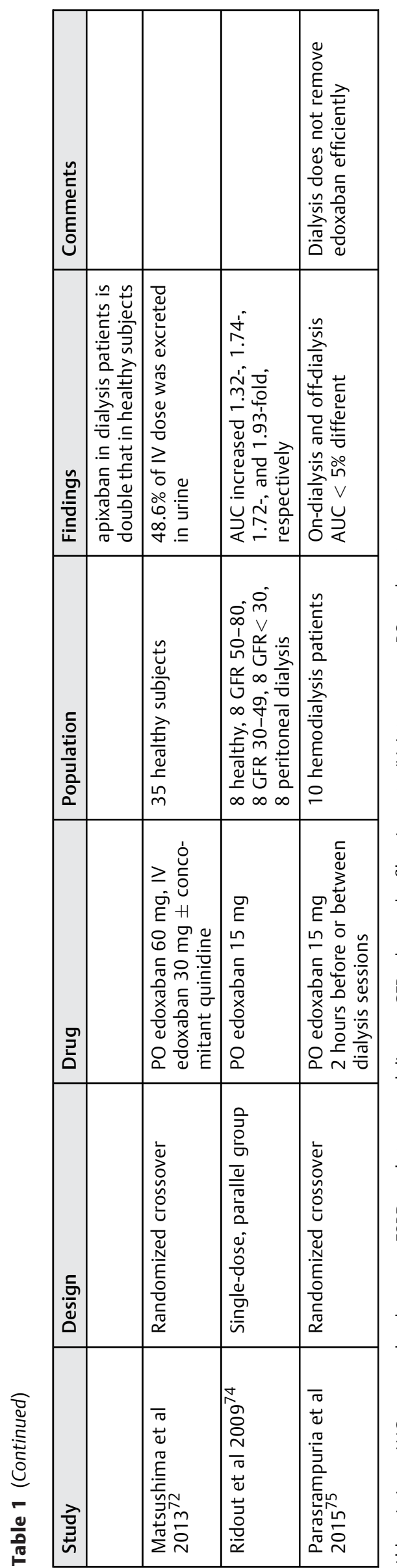

prevalence of dabigatran use in dialysis patients has subsequently dropped, reaching $0.3 \%$ in late $2015 .{ }^{43}$ Results from the Outcomes Registry for Better Informed Therapy for Atrial Fibrillation reflect this trend as well. ${ }^{44}$

\section{Safety in ESRD}

In the setting of a closely monitored phase-I study, three doses of dabigatran (150,110, and $75 \mathrm{mg}$ once) in hemodialysis patients were associated with only one minor bleeding. ${ }^{38}$ Data from shortly after the approval of dabigatran in the United States indicate very high rates of major and nonmajor bleeding with its use in hemodialysis patients ( - Table 4$){ }^{42}$ While these data may reflect erroneous, early use, current data still suggest $39.4 \%$ of dabigatran users for $\mathrm{AF}$ who had a renal indication for dose reduction were still receiving the standard dose. ${ }^{45}$ However, as dabigatran remains contraindicated in ESRD and is seldom used off-label in this population, it is unlikely that more population-based safety data on dabigatran in ESRD will be published.

\section{Rivaroxaban}

\section{Pharmacology in ESRD}

Rivaroxaban, a factor Xa inhibitor, has a renal clearance of $66 \%$ after oral ingestion. Nevertheless, $36 \%$ of ingested rivaroxaban is excreted unchanged in the urine, indicating the renal clearance contribution out of total clearance (-Table 1). ${ }^{46}$ In patients with mild, moderate, and severe CKD, the AUC was augmented by 44,52 , and $64 \%$, respectively, representing significant drug accumulation. ${ }^{47}$ Among eight patients receiving maintenance hemodialysis, a single $15-\mathrm{mg}$ oral dose of rivaroxaban resulted in a $56 \%$ increase in post-dialysis AUC, compared with healthy subjects. ${ }^{48}$ This was concluded by the authors to reflect 35\% decreased clearance in ESRD patients, which recapitulates the findings in patients with moderate CKD. ${ }^{48} \mathrm{~A}$ further study conducted on 18 patients with maintenance hemodialysis confirmed that rivaroxaban was not appreciably removed by dialysis. ${ }^{49}$ Further, this study examined a clinical steady state achieved after 7 days of rivaroxaban at $10 \mathrm{mg}$ daily and demonstrated trough levels which were on par with those observed in patients with moderate CKD in the ROCKET-AF (Rivaroxaban Once Daily Oral Direct Factor Xa Inhibition Compared With Vitamin K Antagonism for Prevention of Stroke and Embolism Trial in Atrial Fibrillation) trial who received $15 \mathrm{mg}$ daily. ${ }^{50}$ Lastly, the AUC with $10 \mathrm{mg}$ of rivaroxaban in ESRD patients in steady state was comparable to that seen in healthy subjects receiving $20 \mathrm{mg} .{ }^{51}$ Of note, this study has been criticized for large interpatient variability, ${ }^{43}$ due to the wide range of trough levels of rivaroxaban $(4.1-93.4 \mu \mathrm{g} / \mathrm{L}$ in six subjects). ${ }^{49}$

\section{Utilization Patterns in ESRD}

Rivaroxaban was approved by the FDA in April 2011 for prevention of stroke and systemic embolism in AF. The above pharmacokinetic studies have led to a change in the FDA labeling of rivaroxaban in August 2016, such that the 15-mg dose pharmacokinetic study was cited with the addition that 


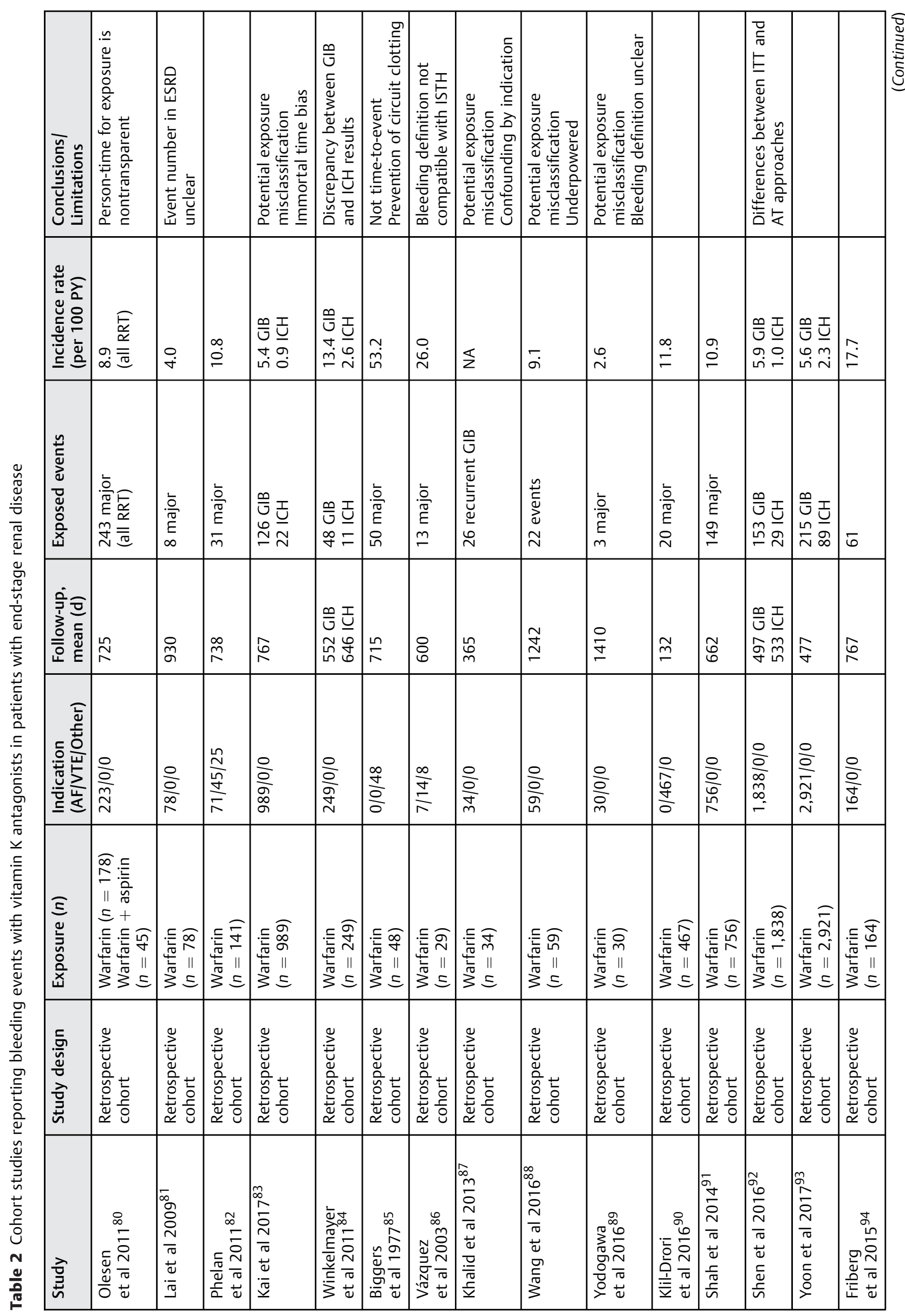




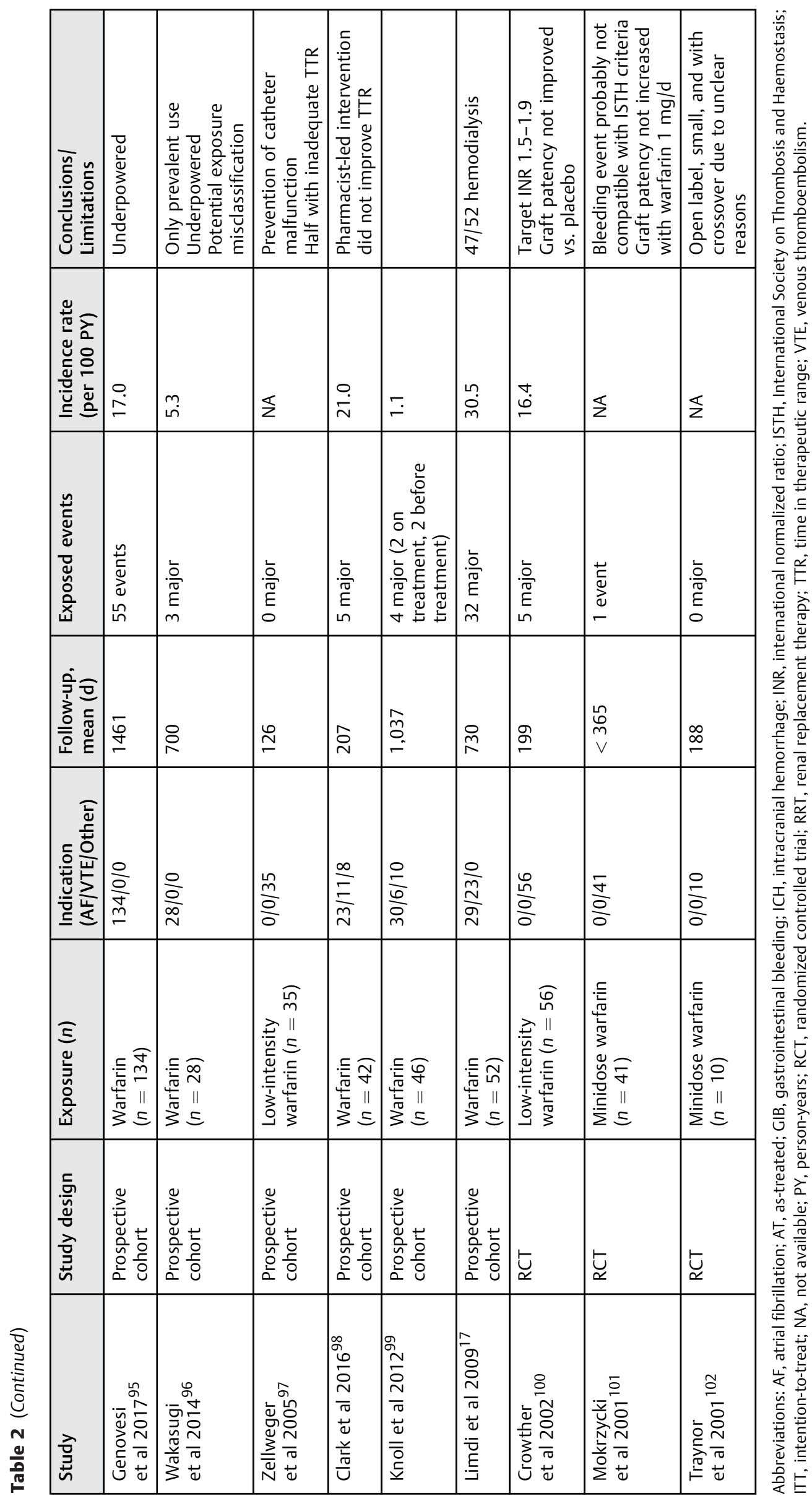





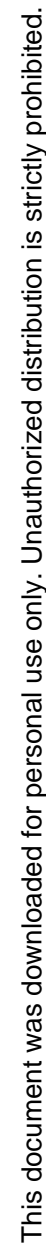


no clinical effectiveness data have been published in ESRD patients. ${ }^{52,53}$ Thus, there is some uncertainty whether the appropriate dose in ESRD patients is 10 or $15 \mathrm{mg}$ daily. The explicitly recommended doses are presented in - Table 3 .

In Europe, rivaroxaban is contraindicated in ESRD. ${ }^{54}$ As of late 2015 , rivaroxaban use was prevalent in $0.8 \%$ of dialysis patients on anticoagulants for $\mathrm{AF}$ in the United States. ${ }^{43}$ Similar to dabigatran, $41.3 \%$ of the non-ESRD patients with renal indication for dose reduction were overdosed. ${ }^{45}$ However, the large majority of rivaroxaban users with ESRD were receiving a 15-mg dose. $^{42}$ Finally, in patients with severe CKD there has been a marked increase in the use of rivaroxaban in the United States. ${ }^{43}$

\section{Safety in ESRD}

Very sparse information exists regarding the safety of rivaroxaban in ESRD patients, and no data on the 10-mg dose. The single study that examined the use of the 15- and 20-mg doses had a very short mean follow-up of 106 days (-Table 4). ${ }^{42}$ Likely due to inappropriate use, a major bleeding rate of 68.4 per 100 person-years was recorded in this population. ${ }^{42}$ This rate is more than 18 -fold higher than the rate observed in patients who experienced worsening renal function during the ROCKET-AF trial. ${ }^{55}$

\section{Apixaban}

\section{Pharmacology in ESRD}

Between 24.5 and $28.8 \%$ of the parent drug apixaban, a factor Xa inhibitor, is recovered in the urine after oral ingestion (-Table 1). ${ }^{56}$ After intravenous infusion, renal clearance contributes 17 to $30 \%$ of the total drug clearance. ${ }^{57}$ Renal function is an important predictor of steady-state drug exposure, which occurs after 3 to 4 days. Thus, patients with moderate renal impairment are likely to have a 70\% higher AUC at steady state at any apixaban dose. ${ }^{58}$ In a study with eight hemodialysis patients receiving a single 5-mg dose, the AUC of apixaban was increased by $36 \%$ compared with healthy subjects. Further, dialysis has been found to have a marginal effect on apixaban exposure, reducing the maximal concentration by $13 \% .{ }^{59}$ Thus, significant accumulation of apixaban at steady state was demonstrated in a subsequent study with six hemodialysis patients who received $2.5 \mathrm{mg}$ apixaban twice a day for 7 days. $^{60}$ This study is important in that it showed that the steady-state AUC and minimal concentration of apixaban at $2.5 \mathrm{mg}$ twice a day taken by hemodialysis patients were well within the range in healthy subjects taking the 2.5-mg dose. ${ }^{58,61}$ However, the effectiveness of such a regimen may be questioned, as these values fall below the 10th percentile of the $5 \mathrm{mg}$ twice a day dose in normal subjects. Finally, the same six hemodialysis patients underwent a washout period and then received $5 \mathrm{mg}$ apixaban twice a day for 7 days with a consequent AUC and minimal concentration which were more than twice those seen in healthy subjects. ${ }^{60}$

\section{Utilization in ESRD}

Apixaban was first approved by the FDA for AF in December 2012. The original label recommended dose reduction to $2.5 \mathrm{mg}$ twice a day for patients with at least two factors out of: serum creatinine $\geq 1.5 \mathrm{mg} / \mathrm{dL}$, age $\geq 80$, and weight $\leq 60 \mathrm{~kg}$. ${ }^{62}$ Following the single-dose pharmacokinetic study mentioned above, the label was changed in January 2014 such that the 5mg twice a day dose was recommended in ESRD patients who are not older adults or underweight ( - Table 3). ${ }^{63}$ Of note, in direct reference to the findings from the steady-state study, a recommendation has been made to reconsider the 5-mg dose in hemodialysis patients. ${ }^{52}$ Concurrently, the use of apixaban is not approved in ESRD patients in Europe. ${ }^{64}$

A large retrospective cohort study from the United States that excluded patients with ESRD has demonstrated that among patients with $\mathrm{AF}$ receiving apixaban with a renal indication for dose reduction, overdosing was very common at $48.5 \%$; importantly, overdosing was associated with doubling of major bleeding rates. ${ }^{45}$ Further, among patients without renal indication for dose reduction, $16.5 \%$ were underdosed; such underdosing was associated with an increased risk of stroke (hazard ratio, 4.87; 95\% confidence interval, 1.30-18.26).

Apixaban has been adopted very rapidly in the United States among patients with hemodialysis and AF, and has reached a point prevalence of $10.5 \%$ in this population in October $2015 .{ }^{43}$ There is currently paucity of information on utilization of off-label DOACs in the severe CKD or ESRD population in Europe. Nonetheless, among the DOACs, it appears that a larger proportion of apixaban users with $\mathrm{AF}$ have baseline CKD. ${ }^{65,66}$ In a survey among European electrophysiology centers, apixaban was indicated as the preferred anticoagulant in moderate CKD, and the lack of data on patients with severe CKD and/or RRT was emphasized. ${ }^{67}$

\section{Safety in ESRD}

Bleeding risk with apixaban in ESRD has been assessed in three studies to date ( - Table 4 ). Two of these studies included only inpatient follow-up. ${ }^{68,69}$ With limited follow-up and selection of only events during admission, any rates of major bleeding in these studies are not comparable to clinical trials. In the third study, matched cohorts of patients with severe CKD who used apixaban or VKA were followed for major and clinically relevant nonmajor bleeding; each cohort comprised 73 patients (27 ESRD) ${ }^{70}$ Apixaban users received $2.5 \mathrm{mg}$ twice a day primarily (61.6\%) and were followed for 369 days. There were 9.5 major bleeding events per 100 person-years, which is 3.5-fold higher than the rate in the Apixaban for Reduction in Stroke and Other Thromboembolic Events in Atrial Fibrillation (ARISTOTLE) trial where most of the study population received $5 \mathrm{mg}$ twice a day. ${ }^{29}$ In ARISTOTLE, major bleeding rates in patients with GFR $<50$ and $>80 \mathrm{~mL} / \mathrm{min} / 1.73 \mathrm{~m}^{2}$ were 3.15 and 1.33 per 100 personyears, respectively. ${ }^{71}$ Thus, there is a suggestion for excessive bleeding with reduced-dose apixaban in patients with severe CKD or ESRD compared with full-dose apixaban in patients with nonsevere CKD or ESRD.

\section{Edoxaban}

\section{Pharmacology in ESRD}

Edoxaban, a factor Xa inhibitor, has a 50\% renal clearance out of total clearance. ${ }^{72}$ After a single dose of $60 \mathrm{mg}, 35.4 \%$ of edoxaban is recovered in urine (-Table 1). ${ }^{73}$ With renal 
impairment, edoxaban exposure increases and is assessed as 1.93-fold higher in recipients of peritoneal dialysis than in healthy subjects. ${ }^{74}$ Edoxaban is not dialyzable and no supplemental dose is needed following a hemodialysis session. ${ }^{75}$

\section{Utilization in ESRD}

Edoxaban (sold in the United States as Savaysa) was approved for use in AF by the FDA in January 2015. The recommended dose in patients with GFR 15 to $50 \mathrm{~mL} / \mathrm{min} / 1.73 \mathrm{~m}^{2}$ is $30 \mathrm{mg}$ once a day with no recommendation for ESRD. ${ }^{76}$ In Europe (where it is sold as Lixiana), there are similar recommendations (- Table 3). ${ }^{77}$ These recommendations by the two regulatory authorities were based on population pharmacokinetic data only, as very few participants with GFR $<50 \mathrm{~mL} / \mathrm{min} / 1.73 \mathrm{~m}^{2}$ were included in the ENGAGE-AF TIMI 48 trial. ${ }^{78}$ To date, there are few reports on the utilization of edoxaban in the ESRD population, and, by late 2015 , it was probably negligible in the United States. ${ }^{43}$

\section{Safety in ESRD}

A clinical trial in Japan reported on 50 patients with GFR 15 to $30 \mathrm{~mL} / \mathrm{min} / 1.74 \mathrm{~m}^{2}$ who used edoxaban $15 \mathrm{mg}$ daily in a nonrandomized fashion (- Table 4). ${ }^{79}$ No major bleeding occurred during a 100-day follow-up. ${ }^{79}$

\section{Conclusion}

VKAs are the most widely used oral anticoagulant among AF patients with ESRD. However, there are abundant reports on excessive bleeding risk associated with its use, as well as challenges in attaining therapeutic anticoagulation. These may have triggered rapid adoption of DOACs among ESRD patients in the United States, which initially may have led to inappropriate dosing and excessive bleeding. While apixaban and rivaroxaban have to date expanded labeling which allows use in ESRD, the dosing is based on single-dose studies which may have underestimated drug accumulation and foreseeable harm. Subsequently, steady-state studies have indicated in both cases a reduced dose. While recommending these doses for use in ESRD patients would align with current safety data, their effectiveness in preventing stroke in AF and recurrent VTE remains to be established. Nevertheless, it is very likely that with further increased use of DOACs in ESRD, more population-based safety and effectiveness data will allow informed dosing and choice of oral anticoagulant.

\section{Conflicts of Interest}

Dr. Tagalakis reports an investigator initiated grant from Sanofi, and consulting and speaker bureau fees from Pfizer, Bristol Myers Squibb, Bayer, and Servier outside the submitted work. Dr. Klil-Drori reports personal fees from Bristol-Myers-Squibb, outside the submitted work.

\section{References}

1 Kidney Disease: Improving Global Outcomes (KDIGO) CKD Work Group. KDIGO clinical practice guideline for the evaluation and management of chronic kidney disease. Kidney Int Suppl 2012;3 (01):1-150
2 Murphy D, McCulloch CE, Lin F, et al; Centers for Disease Control and Prevention Chronic Kidney Disease Surveillance Team. Trends in prevalence of chronic kidney disease in the United States. Ann Intern Med 2016;165(07):473-481

3 Saran R, Robinson B, Abbott KC, et al. US Renal Data System 2016 Annual Data Report: epidemiology of kidney disease in the United States. Am J Kidney Dis 2017;69(03, Suppl 1):A7-A8

4 Jha V, Garcia-Garcia G, Iseki K, et al. Chronic kidney disease: global dimension and perspectives. Lancet 2013;382(9888):260-272

5 Pippias M, Kramer A, Noordzij M, et al. The European Renal Association - European Dialysis and Transplant Association Registry Annual Report 2014: a summary. Clin Kidney J 2017;10(02):154-169

6 Lau YC, Proietti M, Guiducci E, Blann AD, Lip GYH. Atrial fibrillation and thromboembolism in patients with chronic kidney disease. J Am Coll Cardiol 2016;68(13):1452-1464

7 Reinecke H, Brand E, Mesters R, et al. Dilemmas in the management of atrial fibrillation in chronic kidney disease. J Am Soc Nephrol 2009;20(04):705-711

8 Ocak G, Lijfering WM, Verduijn M, et al. Risk of venous thrombosis in patients with chronic kidney disease: identification of high-risk groups. J Thromb Haemost 2013;11(04):627-633

9 Mahmoodi BK, Gansevoort RT, Næss IA, et al. Association of mild to moderate chronic kidney disease with venous thromboembolism: pooled analysis of five prospective general population cohorts. Circulation 2012;126(16):1964-1971

10 Nampoory MR, Das KC, Johny KV, et al. Hypercoagulability, a serious problem in patients with ESRD on maintenance hemodialysis, and its correction after kidney transplantation. Am J Kidney Dis 2003;42(04):797-805

11 Allon M, Brouwer-Maier DJ, Abreo K, et al. Recommended clinical trial end points for dialysis catheters. Clin J Am Soc Nephrol 2017:CJN.12011116

12 Holford NH. Clinical pharmacokinetics and pharmacodynamics of warfarin. Understanding the dose-effect relationship. Clin Pharmacokinet 1986;11(06):483-504

13 Leblond F, Guévin C, Demers C, Pellerin I, Gascon-Barré M, Pichette $\mathrm{V}$. Downregulation of hepatic cytochrome P450 in chronic renal failure. J Am Soc Nephrol 2001;12(02):326-332

14 Dreisbach AW, Japa S, Gebrekal AB, et al. Cytochrome P4502C9 activity in end-stage renal disease. Clin Pharmacol Ther 2003;73 (05):475-477

15 Sakaan SA, Hudson JQ, Oliphant CS, et al. Evaluation of warfarin dose requirements in patients with chronic kidney disease and end-stage renal disease. Pharmacotherapy 2014; 34(07):695-702

16 Yang F, Hellyer JA, Than C, et al. Warfarin utilisation and anticoagulation control in patients with atrial fibrillation and chronic kidney disease. Heart 2017;103(11):818-826

17 Limdi NA, Beasley TM, Baird MF, et al. Kidney function influences warfarin responsiveness and hemorrhagic complications. J Am Soc Nephrol 2009;20(04):912-921

18 Bachmann K, Shapiro R, Mackiewicz J. Influence of renal dysfunction on warfarin plasma protein binding. J Clin Pharmacol 1976;16(10 Pt 1):468-472

19 Ifudu O, Dulin AL. Pharmacokinetics and dialysability of warfarin in end-stage renal disease. Nephron 1993;65(01):150-151

20 Bachmann K, Shapiro R, Mackiewicz J. Warfarin elimination and responsiveness in patients with renal dysfunction. J Clin Pharmacol 1977;17(5-6):292-299

21 Keskar V, Sood MM. Use of oral anticoagulation in the management of atrial fibrillation in patients with ESRD: con. Clin J Am Soc Nephrol 2016;11(11):2085-2092

22 McCullough PA, Ball T, Cox KM, Assar MD. Use of oral anticoagulation in the management of atrial fibrillation in patients with ESRD: pro. Clin J Am Soc Nephrol 2016;11(11):2079-2084

23 Wizemann V, Tong L, Satayathum S, et al. Atrial fibrillation in hemodialysis patients: clinical features and associations with anticoagulant therapy. Kidney Int 2010;77(12):1098-1106 
24 Tan J, Bae S, Segal JB, et al. Treatment of atrial fibrillation with warfarin among older adults with end stage renal disease. J Nephrol 2017

25 Shen JI, Turakhia MP, Winkelmayer WC. Anticoagulation for atrial fibrillation in patients on dialysis: are the benefits worth the risks? Curr Opin Nephrol Hypertens 2012;21(06):600-606

26 Schoorl M, Grooteman MP, Bartels PC, Nubé MJ. Aspects of platelet disturbances in haemodialysis patients. Clin Kidney J 2013;6(03):266-271

27 Connolly SJ, Ezekowitz MD, Yusuf S, et al; RE-LY Steering Committee and Investigators. Dabigatran versus warfarin in patients with atrial fibrillation. N Engl J Med 2009;361(12):1139-1151

28 Patel MR, Mahaffey KW, Garg J, et al; ROCKET AF Investigators. Rivaroxaban versus warfarin in nonvalvular atrial fibrillation. N Engl J Med 2011;365(10):883-891

29 Granger CB, Alexander JH, McMurray JJ, et al; ARISTOTLE Committees and Investigators. Apixaban versus warfarin in patients with atrial fibrillation. N Engl J Med 2011;365(11):981-992

30 Giugliano RP, Ruff CT, Braunwald E, et al; ENGAGE AF-TIMI 48 Investigators. Edoxaban versus warfarin in patients with atrial fibrillation. N Engl J Med 2013;369(22):2093-2104

31 Hayden MR, Kolb LG, Khanna R. Calciphylaxis and the cardiometabolic syndrome. J Cardiometab Syndr 2006;1(01):76-79

32 Nigwekar SU, Zhao S, Wenger J, et al. A nationally representative study of calcific uremic arteriolopathy risk factors. J Am Soc Nephrol 2016;27(11):3421-3429

33 Blech S, Ebner T, Ludwig-Schwellinger E, Stangier J, Roth W. The metabolism and disposition of the oral direct thrombin inhibitor, dabigatran, in humans. Drug Metab Dispos 2008;36(02): 386-399

34 Stangier J, Rathgen K, Stähle H, Mazur D. Influence of renal impairment on the pharmacokinetics and pharmacodynamics of oral dabigatran etexilate: an open-label, parallel-group, singlecentre study. Clin Pharmacokinet 2010;49(04):259-268

35 Heidbuchel H, Verhamme P, Alings M, et al; European Heart Rhythm Association. European Heart Rhythm Association Practical Guide on the use of new oral anticoagulants in patients with non-valvular atrial fibrillation. Europace 2013;15(05):625-651

36 FDA. PRADAXA capsules for oral use. Available at https://www. accessdata.fda.gov/drugsatfda_docs/label/2011/022512s007lbl. pdf. Accessed Aug 16, 2017

37 Liesenfeld KH, Clemens A, Kreuzer J, Brueckmann M, Schulze F. Dabigatran treatment simulation in patients undergoing maintenance haemodialysis. Thromb Haemost 2016;115(03):562-569

38 Khadzhynov D, Wagner F, Formella S, et al. Effective elimination of dabigatran by haemodialysis. A phase I single-centre study in patients with end-stage renal disease. Thromb Haemost 2013; 109(04):596-605

39 Pollack CV Jr, Reilly PA, van Ryn J, et al. Idarucizumab for dabigatran reversal - full cohort analysis. N Engl J Med 2017; 377(05):431-441

40 Blennerhassett R, Favaloro EJ, Pasalic L. Novel (Oral) anticoagulant challenges in surgery. Semin Thromb Hemost 2017;43(07): 706-715

41 Sindet-Pedersen C, Pallisgaard JL, Staerk L, et al. Temporal trends in initiation of VKA, rivaroxaban, apixaban and dabigatran for the treatment of venous thromboembolism - a Danish nationwide cohort study. Sci Rep 2017;7(01):3347

42 Chan KE, Edelman ER, Wenger JB, Thadhani RI, Maddux FW. Dabigatran and rivaroxaban use in atrial fibrillation patients on hemodialysis. Circulation 2015;131(11):972-979

43 Chan KE, Giugliano RP, Patel MR, et al. Nonvitamin K anticoagulant agents in patients with advanced chronic kidney disease or on dialysis with AF. J Am Coll Cardiol 2016;67(24):2888-2899

44 Steinberg BA, Shrader P, Thomas L, et al; Outcomes Registry for Better Informed Treatment of Atrial Fibrillation (ORBIT-AF) Investigators and Patients. Factors associated with non-vitamin $\mathrm{K}$ antagonist oral anticoagulants for stroke prevention in patients with new-onset atrial fibrillation: results from the Outcomes Registry for Better Informed Treatment of Atrial Fibrillation II (ORBIT-AF II). Am Heart J 2017;189:40-47

45 Yao X, Shah ND, Sangaralingham LR, Gersh BJ, Noseworthy PA. Non-vitamin $\mathrm{K}$ antagonist oral anticoagulant dosing in patients with atrial fibrillation and renal dysfunction. J Am Coll Cardiol 2017;69(23):2779-2790

46 Weinz C, Schwarz T, Kubitza D, Mueck W, Lang D. Metabolism and excretion of rivaroxaban, an oral, direct factor Xa inhibitor, in rats, dogs, and humans. Drug Metab Dispos 2009;37(05):1056-1064

47 Kubitza D, Becka M, Mueck W, et al. Effects of renal impairment on the pharmacokinetics, pharmacodynamics and safety of rivaroxaban, an oral, direct Factor Xa inhibitor. Br J Clin Pharmacol 2010;70(05):703-712

48 Dias C, Moore KT, Murphy J, et al. Pharmacokinetics, pharmacodynamics, and safety of single-dose rivaroxaban in chronic hemodialysis. Am J Nephrol 2016;43(04):229-236

49 De Vriese AS, Caluwé R, Bailleul E, et al. Dose-finding study of rivaroxaban in hemodialysis patients. Am J Kidney Dis 2015;66 (01):91-98

50 Mueck W, Schwers S, Stampfuss J. Rivaroxaban and other novel oral anticoagulants: pharmacokinetics in healthy subjects, specific patient populations and relevance of coagulation monitoring. Thromb J 2013;11(01):10

51 Stampfuss J, Kubitza D, Becka M, Mueck W. The effect of food on the absorption and pharmacokinetics of rivaroxaban. Int J Clin Pharmacol Ther 2013;51(07):549-561

52 Deal EN, Shuster JE. Balancing anticoagulation decisions in patients on dialysis with atrial fibrillation. J Am Soc Nephrol 2017;28(07):1957-1959

53 FDA. Xarelto - tablets for oral use. Avilable at https://www. accessdata.fda.gov/drugsatfda_docs/label/2016/202439s017lbl. pdf. Accessed Aug 16, 2017

54 Bayer. Xarelto - prescribing information. Available at http://www. xarelto-info.co.uk/static/new/site-resources/pdfs/prescribing-information.pdf. Accessed Aug 16, 2017

55 Fordyce CB, Hellkamp AS, Lokhnygina Y, et al; ROCKET AF Steering Committee and Investigators. On-treatment outcomes in patients with worsening renal function with rivaroxaban compared with warfarin: insights from ROCKET AF. Circulation 2016;134(01): 37-47

56 Raghavan N, Frost CE, Yu Z, et al. Apixaban metabolism and pharmacokinetics after oral administration to humans. Drug Metab Dispos 2009;37(01):74-81

57 Frost C, Yu Z, Nepal S, et al. Apixaban, a direct factor Xa inhibitor: single-dose pharmacokinetics and pharmacodynamics of an intravenous formulation. J Clin Pharmacol 2008;48(09):1132

58 Leil TA, Feng Y, Zhang L, Paccaly A, Mohan P, Pfister M. Quantification of apixaban's therapeutic utility in prevention of venous thromboembolism: selection of phase III trial dose. Clin Pharmacol Ther 2010;88(03):375-382

59 Wang X, Tirucherai G, Marbury TC, et al. Pharmacokinetics, pharmacodynamics, and safety of apixaban in subjects with end-stage renal disease on hemodialysis. J Clin Pharmacol 2016;56(05):628-636

60 Mavrakanas TA, Samer CF, Nessim SJ, Frisch G, Lipman ML. Apixaban pharmacokinetics at steady state in hemodialysis patients. J Am Soc Nephrol 2017;28(07):2241-2248

61 Kowalski K, Nielsen J, Roy A, et al. Apixaban exposure and anti-Xa activity in nonvalvular atrial fibrillation patients: an application of population PK/PD analysis. J Pharmacokinet Pharmacodyn 2014;41(Suppl 1):7-101

62 FDA. Eliquis tablets for oral use. Available at https://www. accessdata.fda.gov/drugsatfda_docs/label/2014/202155s002lbl. pdf. Accessed Aug 17, 2017

63 FDA. ELIQUIS Supplemental Approval. Available at https://www. accessdata.fda.gov/drugsatfda_docs/appletter/2014/202155orig 1s002ltr.pdf. Accessed Aug 7, 2017 
64 Heidbuchel H, Verhamme P, Alings M, et al. Updated European Heart Rhythm Association Practical Guide on the use of nonvitamin $\mathrm{K}$ antagonist anticoagulants in patients with non-valvular atrial fibrillation. Europace 2015;17(10):1467-1507

65 Staerk L, Fosbøl EL, Lip GYH, et al. Ischaemic and haemorrhagic stroke associated with non-vitamin $\mathrm{K}$ antagonist oral anticoagulants and warfarin use in patients with atrial fibrillation: a nationwide cohort study. Eur Heart J 2017;38(12):907-915

66 Hohnloser SH, Basic E, Nabauer M. Comparative risk of major bleeding with new oral anticoagulants (NOACs) and phenprocoumon in patients with atrial fibrillation: a post-marketing surveillance study. Clin Res Cardiol 2017;106(08):618-628

67 Potpara TS, Lenarczyk R, Larsen TB, Deharo JC, Chen J, Dagres N; Conducted by the Scientific Initiatives Committee, European Heart Rhythm Association. Management of atrial fibrillation in patients with chronic kidney disease in Europe. Results of the European Heart Rhythm Association Survey. Europace 2015;17(12):1862-1867

68 Sarratt SC, Nesbit R, Moye R. Safety outcomes of apixaban compared with warfarin in patients with end-stage renal disease. Ann Pharmacother 2017;51(06):445-450

69 Steuber TD, Shiltz DL, Cairns AC, Ding Q Binger KJ, Courtney JR. A multicenter analysis of factors associated with apixaban-related bleeding in hospitalized patients with end-stage renal disease on hemodialysis. Ann Pharmacother 2017;51(11):954-960

70 Stanton BE, Barasch NS, Tellor KB. Comparison of the safety and effectiveness of apixaban versus warfarin in patients with severe renal impairment. Pharmacotherapy 2017;37(04):412-419

71 Hijazi Z, Hohnloser SH, Andersson U, et al. Efficacy and safety of apixaban compared with warfarin in patients with atrial fibrillation in relation to renal function over time: insights from the ARISTOTLE Randomized Clinical Trial. JAMA Cardiol 2016;1(04):451-460

72 Matsushima N, Lee F, Sato T, Weiss D, Mendell J. Bioavailability and safety of the factor Xa inhibitor edoxaban and the effects of quinidine in healthy subjects. Clin Pharmacol Drug Dev 2013;2 (04):358-366

73 Bathala MS, Masumoto H, Oguma T, He L, Lowrie C, Mendell J. Pharmacokinetics, biotransformation, and mass balance of edoxaban, a selective, direct factor Xa inhibitor, in humans. Drug Metab Dispos 2012;40(12):2250-2255

74 Ridout G, de la Motte S, Niemczyk S, et al. Effect of renal function on edoxaba-f rharmacokjnetics (PK) and on population PK/PKPD model. J Clin Pharmacol 2009;49(09):1124

75 Parasrampuria DA, Marbury T, Matsushima N, et al. Pharmacokinetics, safety, and tolerability of edoxaban in end-stage renal disease subjects undergoing haemodialysis. Thromb Haemost 2015;113(04):719-727

76 FDA. SAVAYSA tablets for oral use. Available at https://www. accessdata.fda.gov/drugsatfda_docs/label/2015/206316lbl.pdf. Accessed Aug 18, 2017

77 EMA. Lixiana - Assessment Report. Available at http://www.ema. europa.eu/docs/en_GB/document_library/EPAR_Product_Informa tion/human/002629/WC500189045.pdf. Accessed Aug 18, 2017

78 Bohula EA, Giugliano RP, Ruff CT, et al. Impact of renal function on outcomes with edoxaban in the ENGAGE AF-TIMI 48 Trial. Circulation 2016;134(01):24-36

79 Koretsune Y, Yamashita T, Kimura T, Fukuzawa M, Abe K, Yasaka M. Short-term safety and plasma concentrations of edoxaban in Japanese patients with non-valvular atrial fibrillation and severe renal impairment. Circ J 2015;79(07):1486-1495

80 Olesen JB, Lip GY, Kamper AL, et al. Stroke and bleeding in atrial fibrillation with chronic kidney disease. N Engl J Med 2012;367 (07):625-635

81 Lai HM, Aronow WS, Kalen P, et al. Incidence of thromboembolic stroke and of major bleeding in patients with atrial fibrillation and chronic kidney disease treated with and without warfarin. Int J Nephrol Renovasc Dis 2009;2:33-37

82 Phelan PJ, O'Kelly P, Holian J, et al. Warfarin use in hemodialysis patients: what is the risk? Clin Nephrol 2011;75(03):204-211
83 Kai B, Bogorad Y, Nguyen LN, et al. Warfarin use and the risk of mortality, stroke, and bleeding in hemodialysis patients with atrial fibrillation. Heart Rhythm 2017;14(05):645-651

84 Winkelmayer WC, Liu J, Setoguchi S, Choudhry NK. Effectiveness and safety of warfarin initiation in older hemodialysis patients with incident atrial fibrillation. Clin J Am Soc Nephrol 2011;6 (11):2662-2668

85 Biggers JA, Remmers AR Jr, Glassford DM, Sarles HE, Lindley JD, Fish JC. The risk of anticoagulation in hemodialysis patients. Nephron 1977;18(02):109-113

86 Vázquez E, Sánchez-Perales C, García-Cortes MJ, et al. Ought dialysis patients with atrial fibrillation be treated with oral anticoagulants? Int J Cardiol 2003;87(2-3):135-139, discussion 139-141

87 Khalid F, Qureshi W, Qureshi S, Alirhayim Z, Garikapati K, Patsias I. Impact of restarting warfarin therapy in renal disease anticoagulated patients with gastrointestinal hemorrhage. Ren Fail 2013;35(09):1228-1235

88 Wang TK, Sathananthan J, Marshall M, Kerr A, Hood C. Relationships between Anticoagulation, Risk Scores and Adverse Outcomes in Dialysis Patients with Atrial Fibrillation. Heart Lung Circ 2016;25(03):243-249

89 Yodogawa K, Mii A, Fukui M, et al. Warfarin use and incidence of stroke in Japanese hemodialysis patients with atrial fibrillation. Heart Vessels 2016;31(10):1676-1680

90 Klil-Drori AJ, Coulombe J, Nessim SJ, Tagalakis V. The risk of major bleeding with low-molecular-weight-heparins for venous thromboembolism in dialysis patients: the Q-VTE Study. Blood 2016;128(22):89-89

91 Shah M, Avgil Tsadok M, Jackevicius CA, et al. Warfarin use and the risk for stroke and bleeding in patients with atrial fibrillation undergoing dialysis. Circulation 2014;129(11):1196-1203

92 Shen JI, Montez-Rath ME, Lenihan CR, Turakhia MP, Chang TI, Winkelmayer WC. Outcomes after warfarin initiation in a cohort of hemodialysis patients with newly diagnosed atrial fibrillation. Am J Kidney Dis 2015;66(04):677-688

93 Yoon CY, Noh J, Jhee JH, et al. Warfarin use in patients with atrial fibrillation undergoing hemodialysis: a nationwide populationbased study. Stroke 2017;48(09):2472-2479

94 Friberg L, Benson L, Lip GY. Balancing stroke and bleeding risks in patients with atrial fibrillation and renal failure: the Swedish Atrial Fibrillation Cohort study. Eur Heart J 2015;36(05):297-306

95 Genovesi S, Rebora P, Gallieni M, et al. Effect of oral anticoagulant therapy on mortality in end-stage renal disease patients with atrial fibrillation: a prospective study. J Nephrol 2017;30(04):573-581

96 Wakasugi M, Kazama JJ, Tokumoto A, et al. Association between warfarin use and incidence of ischemic stroke in Japanese hemodialysis patients with chronic sustained atrial fibrillation: a prospective cohort study. Clin Exp Nephrol 2014;18(04):662-669

97 Zellweger M, Bouchard J, Raymond-Carrier S, Laforest-Renald A, Quérin S, Madore F. Systemic anticoagulation and prevention of hemodialysis catheter malfunction. ASAIOJ 2005;51(04):360-365

98 Clark EG, Rodger MA, Ramsay TO, Knoll GA. Effectiveness of a computerized decision support system for anticoagulation management in hemodialysis patients: a before-after study. Hemodial Int 2016;20(04):530-536

99 Knoll F, Sturm G, Lamina C, et al. Coumarins and survival in incident dialysis patients. Nephrol Dial Transplant 2012;27(01):332-337

100 Crowther MA, Clase CM, Margetts PJ, et al. Low-intensity warfarin is ineffective for the prevention of PTFE graft failure in patients on hemodialysis: a randomized controlled trial. J Am Soc Nephrol 2002;13(09):2331-2337

101 Mokrzycki MH, Jean-Jerome K, Rush H, Zdunek MP, Rosenberg SO. A randomized trial of minidose warfarin for the prevention of late malfunction in tunneled, cuffed hemodialysis catheters. Kidney Int 2001;59(05):1935-1942

102 Traynor JP, Walbaum D, Woo YM, Teenan P, Fox JG, Mactier RA. Low-dose warfarin fails to prolong survival of dual lumen venous dialysis catheters. Nephrol Dial Transplant 2001;16(03):645 